\title{
Engineering Education: Key Features of the Digital Transformation
}

\author{
Anatolii A. Aleksandrov ${ }^{1}$, Yurii B. Tsvetkov ${ }^{1 *}$, and Mikhail M. Zhileykin ${ }^{1}$ \\ ${ }^{1}$ Bauman Moscow State Technical University, 2nd Baumanskaya str., 5/1, 105005, Moscow, Russia
}

\begin{abstract}
The paper deals with the digital transformation of engineering education. Such transformation is justified in terms of an engineering education paradigm change. Based on a comprehensive analysis of the didactic system of engineering education, the authors specify the requirements for such important engineering education components as goal setting, content, educational technologies, assessment tools and methods in current educational environment. They provides examples of a practical digital transformation of a number of engineering curricula and syllabi by integrating blended learning based on a Small Private Online Course (SPOC). The authors share their best practices in designing e-learning taking into account the features of the learning-forgetting process, they demonstrate how to make use of the saved time for students' practical work, how to implement gamification techniques based on such new forms as the Hackathon, Internet of things (IoT) for engineering education. They also provide examples of creating a digital educational environment with specialized software modules to visualize complex mathematical concepts as well as examples of applying principles of artificial intelligence and machine learning to shape a student's adapted educational trajectory. They discuss how to identify student's problems with learning material assimilation and suggest a specially developed course including propaedeutic unit for additional study.
\end{abstract}

\section{Introduction}

In the contemporary context of the fourth industrial revolution, the concept of a technoscience has appeared as a reflection of the new relationship between a science and a technology and their close convergence and interpenetration, symbolizing the fact that the technogenic environment is being transformed from a simple "application" of scientific knowledge into the natural environment of its evolution [1,2]. Currently, a technoscience determines an evolutionary stage of breakthrough, critical technologies in strategic areas of research and development: from nanotechnology to mechatronics, robotics, rocket and space technology, and nuclear and renewable energy. The essential feature of a technoscience while implementing it as critical technologies is an extremely high level of requirements for their quality and efficiency. Therefore, in addition to the term "critical technologies" such concepts as Hi-Tech or knowledge-intensive technologies are used.

\footnotetext{
*Corresponding author: tsvetkov@bmstu.ru
} 
Researching and teaching critical technologies at leading technical universities are based on the natural integrity of practice-oriented and fundamental training. This is the basis for innovations in engineering education [3-14], and thanks to their development and implementation, Bauman Moscow State Technical University has ranked high for almost 200 years. At the same time, aligning the education system with the requirements of the digital economy anticipates the digital transformation of engineering education and shaping new skills in young engineers so that to keep up with the digital age $[15,16]$.

The issue itself is so sophisticated that it has led to numerous approaches and proposals, which are the subject of discussions at international conferences, in various articles and books. In the context of engineering education, the digital transformation is associated with new interactive educational technologies, the development of online and e-learning courses, visualization and gamification of education, the development of academic and applied competencies in future engineers, the introduction of new learning environments, etc. [1718]. These features of the digital transformation are due to ubiquitous access to the Internet, the ability to transmit information over any distance, the widespread use of mobile devices, and the emergence of educational Internet sites available to the unlimited audience. However, these changes cannot be called radical yet, since domestic universities are at the early stage of introducing digital technologies, and the educational process is on the transition from pilot projects to scaling [19]. A gap between the best university practices and the daily activities of professors working in engineering universities can be considered as the main reason of the issue. Thus, from this perspective it is relevant to highlight and analyze the basic principles of the digital transformation of engineering education, consider its key points and examples.

\section{Digitalization: a paradigm shift in engineering education}

If we state a goal of the digital transformation of engineering education as an increase in its efficiency, it is possible to analyze features, problems, and ways of the process consistently. The efficiency increase can be considered from several perspectives. First, to enhance the content of educational curricula and syllabi so that they meet the increasing requirements for learning outcomes and the graduates' competencies, to ensure the achievement of the required educational results by all students. Next, to increase the level of students' cognitive activity, to foster their critical and creative thinking as well as universal competencies, to provide opportunities to develop and satisfy their individual capabilities and cognitive interests. Finally, to improve the possibilities of educational technologies, i.e. methods, structural organization of the educational process, as well as the methodological support in order to increase education efficiency by saving time for both students and professors.

Setting such goals, the digital transformation process essentially involves a change in the entire paradigm of education, which in general implies a change in "how we think, how we act, how we communicate with the external environment and with each other. And in this case, a technology is more a tool than a goal" [20]. A shift in the educational paradigm in a work [21] involving a different content, different approaches, different laws, different relations, different behavior, different pedagogical mentality is similarly specified. At the same time, the recent experience based on the analysis of results and consequences of the radical reforms in various areas including education teaches us not to make previous mistakes, and while moving forward, not to destroy the foundation. Therefore, approaches to change the educational paradigm in the digital transformation of engineering education should be compared with the fundamental provisions of pedagogy based on its classical didactic principles. Thus, it is necessary to adapt these transformations to the form acceptable to academicians, taking into account the requirements of the modern educational process. 


\section{Didactic system of engineering education: structure and transformation experience}

When analysing the digital transformation of engineering education comprehensively and working out proposals on it, it is necessary to distinguish its didactic system as integral education, a set of interrelated components: learning goals, content, a learning process and assessment required to organize training and to achieve intended learning results (fig. 1) [23].

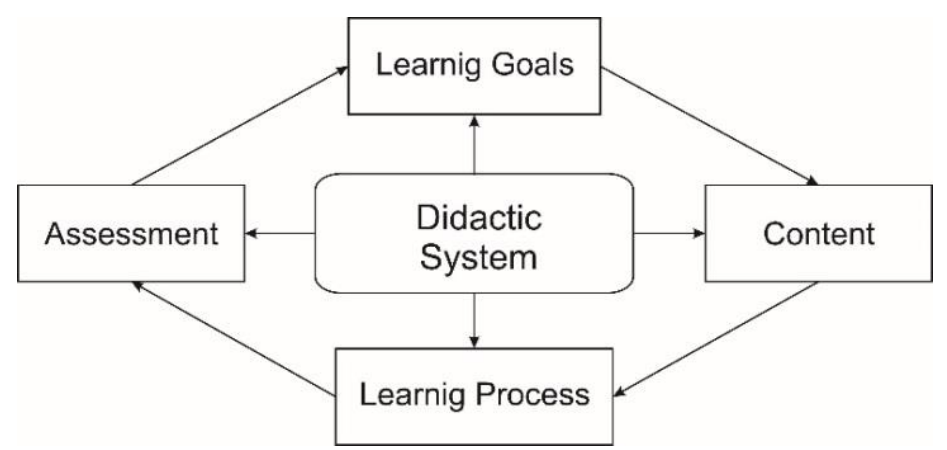

Fig. 1. The structure of the didactic system.

Each of the components of the didactic system of engineering education has some key features that, when coordinated, give a synergistic effect.

\subsection{Goal setting}

Goal setting is the basis for creating a didactic system as a whole. Explicitly set, specified goals can serve as the basis for the development of the course content, the applied methods and learning media, as well as assessment tools and methods that provide diagnostics of the achievement of the set goals. The requirements for learning outcomes in educational standards are usually specified in a very general way. Therefore, in order to assess knowledge and skills that are being formed and to measure them, clear and precise goals are to be set, i.e. their specification is necessary.

Specifying the goals implies setting them in such a way and content that allows an objective assessment of their achievement. The design algorithm of well-described, specific goals consists of the phased implementation of a structural model known in international pedagogy since 1996 [23] and denoted by the abbreviation $A B C D$.

The $A B C D$ model is supposed to include a number of important elements into the structure of the educational goal being formed. The result of specification of this model should be the formulation of a goal that includes

- action, execution;

- condition for action performance,

- criteria for an action performance level.

The functional model of learning goals allows describing them precisely and clearly with extremely definite words.

Mastering a wide range of competencies and acquiring intellectual skills by studying a wide range of subjects, including engineering subjects can be considered as the main way to increase the efficiency of engineering education. Therefore, when designing curricula and setting the educational objectives of the engineering courses, it is necessary to provide appropriate levels of cognitive activity and levels of acquired knowledge as a result of this activity. 
The intellectual skills necessary for this, such as analysis, comparison, synthesis, abstraction, systematization, generalization should be acquired in the educational process together with practical skills such as calculations, modeling, processing measured results, etc. A relevant curriculum can be designed based on a complex, hierarchically ordered classification of the course objectives, i.e. taxonomy. In the most common taxonomy in modern pedagogical practice [24], there are the following levels:

- levels of cognitive activity (The Cognitive Processes Dimension) (Remember, Understand, Apply, Analyze, Evaluate, Create)

- levels of knowledge acquired in cognitive activity (The Knowledge Dimension) (Factual, Conceptual, Procedural, Metacognitive).

The example of the cognitive activity level and the knowledge level in the form of a twodimensional classification is shown in figure 2 .

\begin{tabular}{|c|c|c|c|c|c|c|}
\hline \multirow{2}{*}{$\begin{array}{c}\text { The Knowledge } \\
\text { Dimension }\end{array}$} & \multicolumn{5}{|c|}{ The Cognitive Processes Dimension } \\
\cline { 2 - 7 } & Remember & Understand & Apply & Analyze & Evaluate & Create \\
\hline Factual & Objective 1 & & & & & \\
\hline Conceptual & & Objective 2 & $\begin{array}{c}\text { Objective } \\
3\end{array}$ & & & \\
\hline Procedural & & & & $\begin{array}{c}\text { Objective 4 } \\
\text { Objective 5 }\end{array}$ & & \\
\hline Metacognitive & & & & & & Objective 6 \\
\hline
\end{tabular}

Fig. 2. Model of Learning Objectives

Such two-dimensional classification enables reasonably to form a set of learning outcomes (objectives) that comprehensively determine the level of competencies development in a particular course [25].

\subsection{Content}

Currently, the content of engineering education based on the combination of practiceoriented learning and fundamental training is being increasingly focused on shaping not only professional but also some universal students' competencies. The new content of engineering education provides the transfer of fundamental and technical knowledge as well as the ability to learn autonomously, analyze and solve creative problems using a cross-subject approach. A trained engineer must be proficient in project management methods, be ready for professional communication and teamwork, and possess some other universal competencies. Therefore, the content of engineering education should involve the meaningful principles and provisions of the long-term experience and the features of the digital transformation of curricula for engineering and technology study. The combination of such basic key provisions and principles can be described as the following:

- Goal setting is a backbone of an educational content design. The intended learning outcomes formulated in terms that verify their achievement are the basis for analyzing the course content, monitoring its development and improvement.

- Scientificity ensures the reliability and accuracy of the selected facts and information.

- Shaping cognitive skills facilitates the development of students' thinking skills, selfevaluation, and self-reflection. There are sections that form the initial levels of cognitive 
skills (memorizing information, its reproduction and application), as well as high-level cognitive activity, including the formation of critical thinking (analysis, assessment), the creation of objects of the subject area, their study.

- Systematicity, integrity, and completeness of presentation is structuring the sufficient educational information required to achieve learning outcomes, structuring it by levels of complexity. Sections of educational courses interact with each other, ensuring their integrity and determining the completeness of presentation. The learning material is structured according to the levels of difficulty; the material for compulsory and in-depth study is defined.

- Possibility of choosing an individual learning trajectory is determined by the individual student's features (a level of initial training, speed of perception, activity, etc.).

- Development of creative thinking is based on productive (creative) ways of problems solution, questions, tasks that can be used in other subject areas; shaping skills by the preliminary selection, analysis, and synthesis of the information on a specific topic, the choice and justified ways of problems solution, tasks and complex tasks including students' educational, research and design activities.

- Inter- and cross-disciplinary communications ensure the implementation of a systematic approach; the continuity of previously obtained knowledge; the continuity of certain types of training such as mathematical, technological, design, environmental, etc.

- Practical orientation provides the ability to apply professional terminology, to solve practical problems related to the course goals and intended learning outcomes.

- Providing independent work of the student some questions, tasks, assignments for self-assessment are given, as well as materials that fill the gaps in the initial students' knowledge.

- Adaptation of educational information, ergonomics of the educational edition. Learning information is adapted according to the level of difficulty so that students can comprehend it. The efficiency of learning material assimilation is ensured by improving its clarity and demonstrativeness, i.e. ergonomic quality.

\subsection{Educational technologies}

Educational technologies, like any others, can be considered as a set of methods and means to achieve a given result, goal. The high level of required learning outcomes in engineering curricula design, their continuous expansion in volume, and an increase in the levels of cognitive activity prescribed in them - all this has predetermined a wide range of the applied educational techniques. The distinguishing feature of modern engineering education is that digital technologies are, firstly, important sections of the studied subject areas, and secondly, they are used to improve the efficiency of didactic systems.

The creation of globally competitive new generation products is based on the widespread use of digital modeling and design methods. The means of implementing these methods are automated digital systems:

- CAD - Computer Aided Design system

- CAE (Computer-aided engineering) - the system for automation of engineering calculations and analysis

- CAM (Computer-aided manufacturing) — the system for automated development of programs for machining parts for $\mathrm{CNC}$ machines

- PDM - Product Data Management system

- PLM - Product Lifecycle Management technology.

- CALS - Continuous Acquisition and Life-cycle Support

- MatLab, Mathcad, Mathematica, Maple — advanced integrated math software 
Digital design and modeling systems are an integral part of the modern engineering curricular content, and mastering them is one of the mandatory competencies for educators of a particular course.

On the other hand, the continuously increasing variety of formats, methods, strategies, techniques, approaches, and tools for organizing e-learning, partially listed in Table 1 [26], causes anxiety of technical university academicians to it.

Table 1. Modern educational technologies.

\begin{tabular}{|c|c|c|c|}
\hline \multicolumn{2}{|c|}{$\begin{array}{l}\text { Formats - } \\
\text { ways, delivery channels }\end{array}$} & \multicolumn{2}{|c|}{$\begin{array}{l}\text { Methods - } \\
\text { forms of content presentation }\end{array}$} \\
\hline $\begin{array}{l}\text { - resident instruction } \\
\text { - e-learning } \\
\text { - distance } \\
\text { - blended }\end{array}$ & $\begin{array}{l}\text { - native } \\
\text { - } \text { mobile } \\
\text { - self-study }\end{array}$ & $\begin{array}{l}\text { - lecture } \\
\text { - interactive } \\
\text { lesson } \\
\text { - training } \\
\text { - case analysis }\end{array}$ & $\begin{array}{l}\text { - } \text { business } \\
\text { simulations } \\
\text { - business/ } \\
\text { role-playing } \\
\text { games } \\
\text { - microlearning } \\
\text { - } \text { social learning }\end{array}$ \\
\hline \multicolumn{4}{|c|}{$\begin{array}{c}\text { Learning strategy - a strategy to achieve learning objectives and outcomes that defines } \\
\text { the formats, methods, techniques, and ways to organize learning }\end{array}$} \\
\hline \multicolumn{2}{|l|}{$\begin{array}{l}\text { - } \text { practice-oriented } \\
\text { - self-organizing } \\
\text { - collaborative } \\
\text { - gaming }\end{array}$} & \multicolumn{2}{|c|}{$\begin{array}{l}\text { - } \text { problem-oriented } \\
\text { - project } \\
\text { - skill } \\
\text { - problem-search }\end{array}$} \\
\hline \multicolumn{2}{|c|}{$\begin{array}{c}\text { Techniques - } \\
\text { methods and tools of } \\
\text { visualization/implementation of pedagogical } \\
\text { methods }\end{array}$} & \multicolumn{2}{|c|}{$\begin{array}{l}\text { Incentives, organization - } \\
\text { methods and tools to organize learning, } \\
\text { the motivation of students }\end{array}$} \\
\hline $\begin{array}{l}\text { - video } \\
\text { - podcast } \\
\text { - infographics } \\
\text { - blog }\end{array}$ & $\begin{array}{l}\text { - virtual/augmented } \\
\text { reality } \\
\text { - textbooks (including } \\
\text { electronic) } \\
\text { - chat bot }\end{array}$ & $\begin{array}{l}\text { - gamification } \\
\text { - linear learning } \\
\text { - personalization } \\
\text { of learning } \\
\text { - adaptive } \\
\text { learning }\end{array}$ & $\begin{array}{l}\text { - } \text { mass/elective } \\
\text { learning } \\
\text { - open learning } \\
\text { - flipped learning }\end{array}$ \\
\hline
\end{tabular}

In recent years, public attention has been attracted to publicly available open online courses Massive Open Online Courses (MOOCs) [27]. When MOOCs emerged, many educators believed it to have a significant impact on the higher education market. In 2013, the interest in them peaked (fig.3), and then began to decline. 


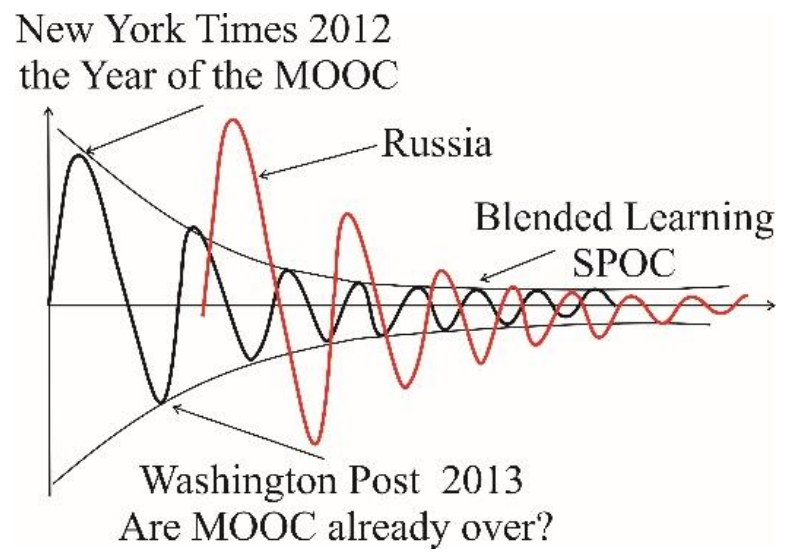

Fig. 3. The cycle of online courses promotion.

This happened due to criticism of the pedagogical potential of the most emerging MOOCs, as well as the lack of a clear financial model for their sustainable functioning.

It seemed doubtful that universities that made course materials available to the public would be willing to continue to fund their course, allocate funds for the development of new and updating existing courses. The potential of MOOCs as a sustainable opportunity for open learning and teaching remained unclear. By 2014, disappointment in the potential of MOOCs increased, MOOCs were defined as a little promising innovation (fig. 3).

Basing on our own experience and the consolidated experience of leading domestic [2830] and foreign universities (Berkeley, California, Harvard, MIT) [31], blended learning can be considered as one of the most effective formats of engineering education at present days. Blended learning involves the integration of classroom and extracurricular learning activities combining traditional and e-learning technologies. It is this format and the flipped classroom method similar to it that makes it possible to implement both key didactic requirements and several innovative educational technologies. The main value of these methods is the opportunity to organize regular autonomous student's work starting from the first week of the term due to preliminarily designed electronic educational resources available to students online at any convenient time.

Such educational process design enables students to work at the necessary course units in order to be ready for the next class work guided by a teacher. This allows enhancing the content of the studied subject area while increasing the level of students' cognitive activity in the educational process: applying the learnt information in practice, analyzing and evaluating the obtained results, creating new technical objects. As a result, the classroom time can be used for gamification instead of lectures.

A mandatory requirement for the method effectiveness is regular monitoring students' preparedness, their progress in mastering the subject. It motivates students to work regularly, allows them to adapt the educational process to the abilities and capabilities of each student, to shape their individual educational trajectories (adaptive learning adaptive teaching).

\subsection{Assessment tools and methods}

Assessment tools and methods typically include assessment assignments or tests, as well as descriptions of forms and procedures in order to determine the quality of mastering the course material by students, to measure a degree of their competence maturity, both as a whole and as its individual components. Tests and measuring materials used for this should clearly demonstrate the degree of students' knowledge and skills in quantitative and qualitative terms. 
The assessment process should be organized on a single methodological basis and meet key didactic requirements. It should be:

- valid (the assessment objects must correspond to the set goals of the academic discipline);

- reliable (uniform agreed criteria or standards should be used);

- fair (different students should have equal opportunities to achieve success);

- developing (to record what students can do and how they can improve their results);

- well-timed (supporting progressive feedback);

- effective (feasible, but not taking a lot of time of professors and students).

The effectiveness of the assessment tools and methods is determined by the technologies used for monitoring learning outcomes, which provide the opportunity of a comprehensive assessment of various curricula components that form the acquired competencies. At the same time, assessment tools and methods should allow measuring the level of achievement of the established learning outcomes. Therefore, when designing innovative assessment tools and methods in order to evaluate the level of students' competencies development, it is necessary to provide a simulation of their professional activities that requires searching for problems and applying the obtained knowledge to solve the problems, combining various ways of activity, and performing other creative procedures [32].

As shown in section 1.1, in the world university practice Bloom's classification (taxonomy) is used to describe the results of curricula acquisition. He proposed a classification of mental behavior from the simple facts reproduction to the process of analysis and assessment. Since Bloom's Taxonomy provides a ready-made structure and a list of verbs, it can be argued that its employment is a key to describe learning outcomes and to design appropriate assessment tools and methods [25]. At the same time, the analysis of advancement (testing) questions in the engineering educational editions shows that, in fact, most of them are not questions at all but just the titles of editions chapters. Students are supposed to enunciate the content of these chapters (as a rule, by heart) and, at the very best, prove that they understand what it is about. This approach enables just to evaluate the elaboration and initial assimilation of the learning material - terminology memorization, basic concepts and definitions, at best to comprehend the relationships between them.

The subject acquisition at the initial level is, of course, necessary for the student's confident advancement along the trajectory of the chosen curriculum. However, modern educational standards - both domestic and foreign - consider the formation of students' highlevel thinking skills as the main goal of training. Based on the requirements for the learning outcomes of the course, stated in the form of diagnosable goals, it is possible to compile a list of knowledge, skills, general and professional competencies to be monitored and evaluated within this course, including the level feature of the learning outcomes.

A methodology to design assessment tasks and tests includes the following stages:

1. Content analysis of the tested competence.

2. Defining key units of the learning material, basic learning elements, and logicalstructural relationships that form the competence.

3. Development of advanced (testing) questions, assignments, and tasks for each learning element, which should be related to the assessed competence.

4. Arranging tasks according to the cognitive process levels and the amount of knowledge acquired in this process.

5. Providing training assignments, testing questions with practice-orientation necessary to shape the required skills.

6. Providing opportunities for self and peer assessment. 
The development of testing and measuring materials for engineering subjects has its own special features. Mastering the leaning material at the initial level of cognition - memorizing, with its absolute importance and necessity, is the least attractive and least interesting activity for students, especially if it is carried out in the form of simple repetition and drilling. Therefore, testing questions at this level are required to be presented in the form of tasks that provide elaboration of learning material, they should be considered from various perspectives, e.g.:

- comparison,

- defining the goal of the process,

- establishing characteristic features, signs or properties of objects and phenomena,

- classification of objects and phenomena according to the specified criterion,

- defining the meaning of a phenomenon, process, explanation, justification,

- conclusions and generalizations.

Tests are increasingly used as assessment tasks now. They can be effectively used in course books as well as for autonomous study and course material revision. In order to encourage students at the initial stage of study, entertaining forms of self-examination can also be employed, e.g. crossword puzzles with encrypted concepts and terms. It facilitates better acquisition of the factual material, increases learning efficiency, requires reflection and analysis [33]. The self- verification of higher levels of knowledge and cognitive activity involves designing advanced questions and tasks in the corresponding subject area of engineering education based on the previously considered two-dimensional taxonomy of goals [25].

\section{Experience in engineering education transformation}

The digital transformation of the key components of the engineering education didactic system can have its own key features in various subject areas while maintaining the unity of fundamental approaches. Modern engineering systems have a complex hierarchical structure. Therefore, when designing them a systematic approach is important, involving both the analysis of the entire system as a whole and its decomposition into components. To demonstrate the unified didactic principles to design modern engineering curricula, let us single out subject areas that provide training in knowledge intensive technologies in various areas of engineering, such as (fig. 4):

- Special purpose vehicles,

- Microtechnologies. 


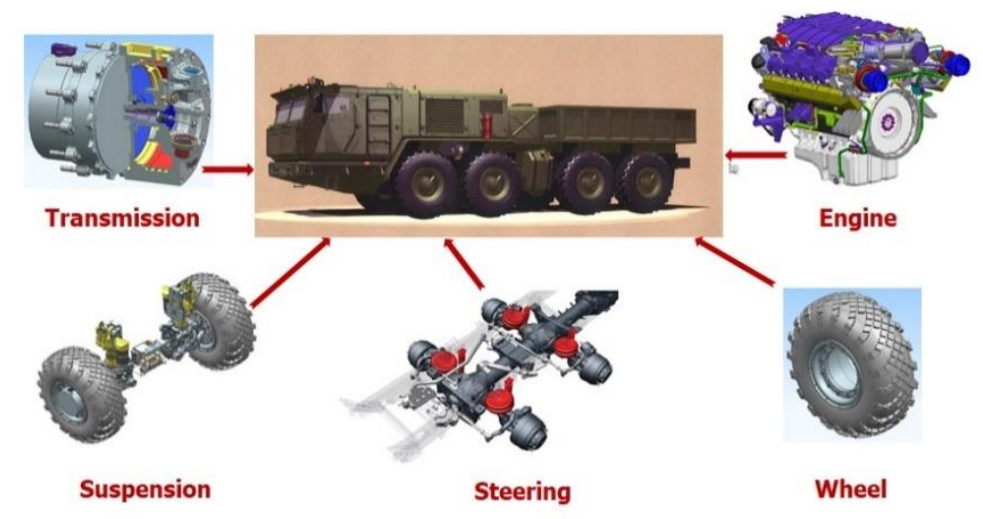

(a)

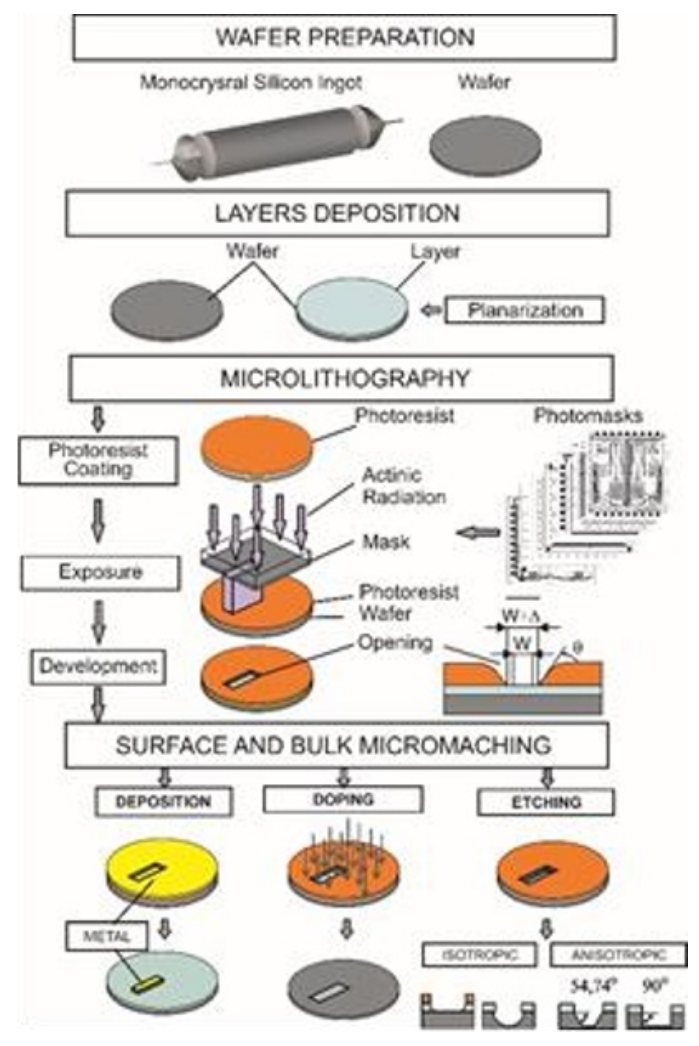

(b)

Fig. 4. The complex structure of technical systems: (a) special purpose vehicles, (b) microtechnology processes.

These two curricula, despite the drastic difference in their subject areas, are implemented by the same didactic principles. First of all, the goal-setting in both cases supposes updating the curriculum content to the level of modern world requirements to the relevant subject areas. A system of blended learning with a "flipped classroom" technology based on electronic educational resources, including online courses available to students via the 
Internet, has been implemented as an educational technology. This model of the educational process design, known as SPOC (Small Private Online Course) [34-36], is the most effective compared to both traditional lecture courses and massive open online courses [37].

In order to ensure students' active regular autonomous work from the first week of the term, electronic course books have been developed [38-42]. They are available to students via the Internet at any convenient time. Mobile versions of these e-manuals placed on students' tablets and smartphones provide students with complete autonomy. The free time saved due to the distance components is used to increase the number of seminars and practical classes with students. The digital form of presenting educational resources facilitates the content curation, i.e. its regular updating and improving.

The key point of the technology implementation is the regularity of student's communication with the professor in the course of mastering a learning material and performing an in-process/progress assessment. The formative/intermediate assessment in the form of a distributed exam increases the students' responsibility, motivates them to work regularly during the term. At the same time, face-to-face classes guided by a professor ensures full students' immersion in the learning environment (fig. 5). It increases the efficiency of the educational process in leading foreign and domestic technical universities as well $[43,44]$.

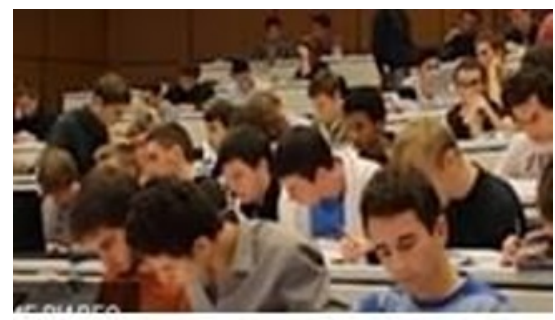

(a)

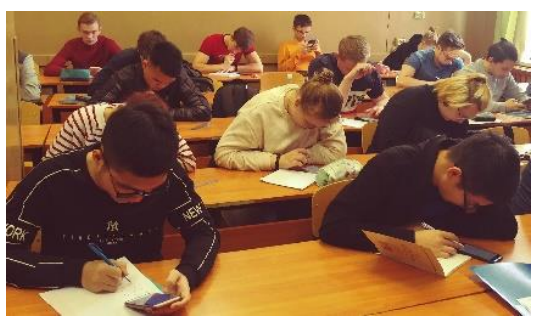

(b)

Fig. 5. Classroom work in blended learning environment: (a) École Polytechnique Fédérale de Lausanne, b - Bauman Moscow State Technical University

It is essentially to structure the course by logically completed modules with closely related content. Constant use of the key subject concepts through the whole course of the study, their application for real tasks solution enables to increase the efficiency of learning material acquisition due to the impact on the "learning-forgetting" process (fig. 6) [45-47].

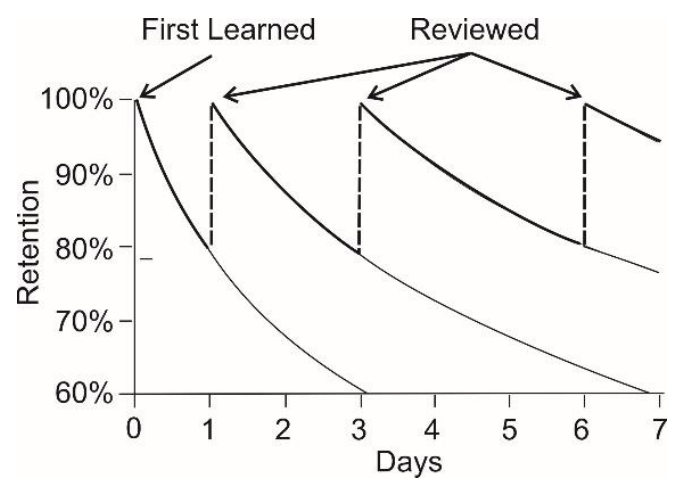

Fig. 6. The learning - forgetting curve. 
Regular monitoring the learning material assimilation is the basis for designing an adaptive educational process, which takes into account the features of each student and student's preparedness. This approach has already been applied to natural science and mathematical training based on information and educational environment for the mathematical training of engineers NOMOTEX [48, 49]. In this environment, specialized software modules are used to visualize the most complex mathematical concepts, for example, tensor fields [50]. Moreover, created on the principles of artificial intelligence, this environment includes a mathematical knowledge base founded on a neural network structure [51]. This allows to shape the optimal, if necessary, individual educational trajectory of a student for the intended learning outcomes. At the same time, the elements of machine learning built into the environment make it possible on time to identify problems that a student may have with the learning material assimilation and offer him/her specially designed course sections including propaedeutic for additional study. Students' regular work including autonomous work allows them to redistribute their workload and organize a continuous longterm (3-4 terms) workshop. Its main goal is to provide students with real engineering skills in laboratories, scientific and educational centers of the University or at leading enterprises by means of their direct participation in solving actual scientific and industrial problems with the disclosure of their individual aptitudes and abilities. [52, 53].

\section{Conclusion}

The digital transformation of engineering education based on the comprehensive change of its didactic paradigm has resulted in increasing engineering education efficiency. The essential components of the current educational didactic system are goal-setting, content, educational technologies, and assessment tools and methods. The paper has provided practical examples of the digital transformation of engineering education at Bauman University including the implementation of a blended learning system based on SPOC (Small Private Online Course). To create a solid digital transformation strategy, you must work collaboratively, identifying your core aims and goals, as well as the technologies, methodologies and innovations you will need. The authors have shared their experience and best practice in designing e-learning courses based on key features of the learning-forgetting process. They have described the opportunity to employ the saved time due to the digital transformation of education for students' permanent workshops, how to apply gamification techniques at technical university as in the case of Hackathon and the Internet of Things. The university graduates have to acquire not only profound knowledge but also unique skills and competencies to be successful. It is important to create new digital learning environment so that to keep up with new requirements to graduates' professional competences and skills. The authors have presented examples of creating a digital environment based on specialized software modules to visualize the most complex mathematical concepts. They have discussed the ways of applying the principles of artificial intelligence and machine learning to shape students' adapted educational trajectory, to reveal students' problems with the learning material assimilation and have offered them specially designed course including propaedeutic unit for additional study. This course is considered as an integrated part of an e-learning environment. 


\section{References}

1. A.L. Andreev, Technoscience, Philosophy of Science, No. 16, p. 201 (2011)

2. V.S. Koshik, Methodological Potential of Synergy in the Development of Critical Technologies, Humanitarian Bulletin, No. 5, pp. 2-2 (2019)

3. A.A. Aleksandrov, et al., The Concept of Complex Continuous Education Using Innovative Information Technologies, Scientific Review: Humanitarian Research, No. 4, pp. 38-42 (2012)

4. A.A. Aleksandrov, Bauman Moscow State Technical University: experience, traditions, and innovations in training engineering and scientific personnel, Engineering education, No. 10, pp. 6-13 (2012)

5. A.A. Aleksandrov, I.B. Fyodorov, V.E. Medvedev, Engineering education today: problems and solutions, Higher education in Russia, No. 12 (2013)

6. A.A. Aleksandrov, S.V. Korshunov, Yu.B. Tsvetkov, Educational standards of Bauman Moscow State Technical University. The new quality of engineering education//Mechanical engineering and computer technologies, No. 12 (2014)

7. A.A. Aleksandrov, Yu.I. Dimitrienko, Mathematical and computer modeling - the basis of modern engineering sciences, Mathematical modeling and numerical methods, No. 1 (1) (2014)

8. A.A. Aleksandrov, et al., Implementation of the innovative educational concept at the "Avionics" engineering center, Innovation in education, No. 3, pp. 4-14 (2017)

9. A.A. Aleksandrov, V.A. Devisilov, M.V. Ivanov, A role of education system in creation of safety culture, Chemical Engineering Transactions, Vol. 53, pp. 211-216 (2016)

10. Yu.V. Panfilov, Yu.B. Tsvetkov, A.I. Belikov, Professionally-oriented training of students in the field of electronic technologies and nanoengineering, Quality management of engineering education. University opportunities and industry needs, pp. 61-63 (2016)

11. M.G. Sergeeva, M.S. Mohammad Anwar, T.G. Stanchuliak, N.N. Bedenko, T.Y. Tsibizova, Organisational economic mechanism of managing the growth of higher education services quality, Espacios, Vol. 39, No. 21, p. 10 (2018)

12. G.O. Kotiev, B.V. Padalkin, A.B. Kartashov, A.S. Dyakov, Designs and development of Russian scientific schools in the field of cross-country ground vehicles building, ARPN Journal of Engineering and Applied Sciences, Vol. 12, No. 4, pp. 1064-1071 (2017)

13. A.A. Aleksandrov, P.A. Kapyrin, N.A. Meshkov, K.A. Neusypin, A.E. Popovich, A.V. Proletarsky, Gamification in the advanced higher professional education: fundamentals of theory and experience of use, International Journal of Civil Engineering and Technology, Vol. 9, No. 11, pp. 1800-1808 (2018)

14. M.G. Sergeeva, S.N. Rozhnov, V.V. Zotov, S.V. Rachek, T.Y. Tsibizova, N.Y. Terekhova, I.V. Poliakova, Legal culture as a basic component of professional training in vocational education, International Journal of Innovative Technology and Exploring Engineering, Vol. 8, No. 12, pp. 4090-4094 (2019)

15. A.Yu. Uvarov, Education in the world of digital technologies: towards digital transformation, Moscow: GU-HSE Publishing House (2018)

16. P.S. Chubik, M.P. Chubik, Industrialization as the main driver of the transformation of engineering education, Engineering education: the course for a new industrialization, Engineering education, No. 10, pp. 66-75 (2012)

17. S.V. Barabanova, A.A. Kaibiyainen, N.V. Kraisman, Digitalization of engineering education in a global context (review of international conferences), Higher education in Russia, No. 1 (2019)

18. V.M. Prikhodko, A.N. Soloviov A. N. How will modern engineering education be? (Thoughts of forum participants), Higher education in Russia, No. 3 (2015) 
19. https://www.kommersant.ru/doc/4033337

20. https://www.bcg.com/ru-ru/about/bcg-review/digitalization.aspx

21. G.Ya. Tsibulko \& M.V. Pshenichniy, Change of educational paradigm as a leading trend of innovative changes in the system of modern education, Young scientist, (2), pp. $862-865$ (2016)

22. M.A. Choshanov, E-Didactics: A new look at learning theory in the digital age, Educational technology and society, 16(3) (2013)

23. R. Heinich, M. Molenda, J. D. Russell, S. E. Smaldino, Instructional Media and Technologies for Learning, Englewood Cliffs, NJ: Merrill (1996)

24. L.W. Anderson, D.R. Krathwohl, eds., A taxonomy for learning, teaching, and assessing: A revision of Bloom's taxonomy of educational objectives, New York: Longman (2001)

25. Y.B. Tsvetkov, Special Aspects of Learning Objectives Design for Disciplines in Engineering Education, Science \& Education of Bauman MSTU, Nauka i Obrazovanie of Bauman MSTU, (3) (2015)

26. Transformation of the system of additional professional education in the digital age. Professional development program for university managers, Kochubey Center, HSE. https://busedu.hse.ru/mirror/pubs/share/310045352 (2019)

27. A.Yu. Uvarov, E. Gable, I.V. Dvoretskaya, I.M. Zaslavsky, I.A. Karlov, T.A. Mertsalova ... \& I. D. Frumin, Difficulties and prospects of the digital transformation of education (2019)

28. S.B. Veledinskaya \& M.Yu. Dorofeeva, Organization of the educational process in a university on blended learning technology, XI International Scientific and Methodological Conference "New Educational Technologies in Higher Education",Yekaterinburg, No. 11 (2014)

29. S.V. Kalmykova \& E.M. Razinkina, The Use of Online Courses in the Model of Blended Learning for Engineering Staff Training (SPbPU Experience), Information Resources of Russia, (3), pp. 37-41 (2017)

30. A.I. Chuchalin, Engineering education in the era of the industrial revolution and the digital economy, Higher education in Russia, (10) (2018)

31. L. Li, MOOCs and SPOCs: Evolution and inheritance of online education, International Conference on Education, Management, Computer and Society, Atlantis Press, January (2016)

32. N.F. Efremova, Assessment quality as a guarantee of competent learning of students, Higher education in Russia, (11) (2012)

33. A.F. Tretiyakov, Technology of structural materials. Course of lectures: a textbook for universities, A. F. Tretiyakov, Moscow: Publishing House of Bauman Moscow State Technical University, p. 327, ill. + CD-ROM, Bibliography: p. 325-327 (2010)

34. M. Zheng, C.C. Chu, Y.J. Wu \& W. Gou, The mapping of on-line learning to flipped classroom: Small private online course, Sustainability, 10(3), p. 748 (2018)

35. F.J.D. Cepeda, Small Private Online Research: A Proposal for A Numerical Methods Course Based on Technology Use and Blended Learning, International Association for Development of the Information Society (2017)

36. N.N. Datsun, SPOC in higher education: the European experience, Education questions, No. 1 (2019)

37. J.P. Jong, The effect of a blended collaborative learning environment in a small private online course (SPOC): A comparison with a lecture course, Journal of Baltic Science Education, 15(2), p. 194 (2016)

38. M.M. Zhileykin, Theoretical foundations for improving the stability and controllability of wheeled machines based on fuzzy logic methods, Moscow: Publishing House of Bauman Moscow State Technical University, p. 238, [1] p. (2016) 
http://ebooks.bmstu.ru/catalog/124/book1368.html

39. M.M. Zhileykin, Modeling of vehicle systems: methodological guidelines for laboratory work, Moscow: Publishing House of Bauman Moscow State Technical University, p. 97 (2017)

http://ebooks.bmstu.ru/catalog/124/book1640.html

40. M.M. Zhileykin, G.O. Kotiev, E.B. Sarach, Mathematical models of vehicle systems: a training manual, Moscow: Publishing House of Bauman Moscow State Technical University, p. 98 (2018). http://ebooks.bmstu.ru/catalog/124/book1715.html

41. S.P. Bychkov, P. Mikhailov, Yu.V. Panfilov, Yu.B. Tsvetkov, edited by Yu.B. Tsvetkov, A Physical fundamentals of the micro- and nanotechnologies, Moscow: Publishing House of Bauman Moscow State Technical University, p. 176 (2009)

http://ebooks.bmstu.ru/catalog/44/book634.html

42. Yu.B. Tsvetkov, Microtechnology processes and equipment. Modules 1 and 2: training manual, Moscow: Publishing House of Bauman Moscow State Technical University, p. $122(2018)$

http://ebooks.bmstu.ru/catalog/44/book1915.html

43. Online Course Electrotechnique II. École Polytechnique Fédérale de Lausanne via edX. https://www.classcentral.com/course/edx-electrotechnique-ii-1618

44. A.A. Aleksandrov, et al., The concept of comprehensive continuous learning using innovative information technologies, Scientific Review: Humanitarian Research, No. 4, pp. 38-42 (2012)

45. V.Yu. Stroganov, et al., Models of forgetting educational information for personnel training system, Automation and control in technical systems, No. 4-1, p. 120-127 (2013)

46. Y.W. Sol, Effective review methods based on the Ebbinghaus' forgetting curve, Journal of Learning Strategy Intervention, 7(1), pp. 1-18 (2016)

47. B.A. Chun \& H.J. Heo, The effect of flipped learning on academic performance as an innovative method for overcoming ebbinghaus' forgetting curve, Proceedings of the 6th International Conference on Information and Education Technology, pp. 56-60, January (2018)

48. https://nomotex.bmstu.ru/.

49. Yu.I. Dimitrienko, E.A. Gubareva, M.P. Gordin, New Methods of Teaching Course "Mathematical Analysis" in Digital Environment "NOMOTEX" for Engineers, Innovative Development, No. 8, pp. 8-11 (2018)

50. Yu.I. Dimitrienko, E.A. Gubareva, S.V. Sborshchikov, Visualization of tensor fields based on the geometric representation of tensors, Scientific visualization, Vol. 10, No. 2, pp. $95-111$ (2018)

51. Yu.I. Dimitrienko, E.A. Gubareva, New technology of mathematical training of engineering personnel based on a neural network model of knowledge, Innovations in education, No. 11, pp. 129-140 (2017)

52. Yu.V. Panfilov, Yu.B. Tsvetkov, A.I. Belikov, Professionally-oriented training of students in the field of electronic technologies and nanoengineering, Quality management of engineering education. University opportunities and industry needs, pp. 61-63 (2016)

53. Y.V. Panfilov, S.B. Nesterov, L.L. Kolesnik, S.V. Sidorova \& Y.B. Tsvetkov, Modern trends of student training on vacuum technic and technology, Journal of Physics: Conference Series. - IOP Publishing, Vol. 1313, No. 1, p. 012043 (2019) 